NASA/TM-2006-214108

\title{
Computer Aided Design of Ka-Band Waveguide Power Combining Architectures for Interplanetary Spacecraft
}

Karl R. Vaden

Glenn Research Center, Cleveland, Ohio 
Since its founding, NASA has been dedicated to the advancement of aeronautics and space science. The NASA Scientific and Technical Information (STI) Program Office plays a key part in helping NASA maintain this important role.

The NASA STI Program Office is operated by Langley Research Center, the Lead Center for NASA's scientific and technical information. The NASA STI Program Office provides access to the NASA STI Database, the largest collection of aeronautical and space science STI in the world. The Program Office is also NASA's institutional mechanism for disseminating the results of its research and development activities. These results are published by NASA in the NASA STI Report Series, which includes the following report types:

- $\quad$ TECHNICAL PUBLICATION. Reports of completed research or a major significant phase of research that present the results of NASA programs and include extensive data or theoretical analysis. Includes compilations of significant scientific and technical data and information deemed to be of continuing reference value. NASA's counterpart of peerreviewed formal professional papers but has less stringent limitations on manuscript length and extent of graphic presentations.

- TECHNICAL MEMORANDUM. Scientific and technical findings that are preliminary or of specialized interest, e.g., quick release reports, working papers, and bibliographies that contain minimal annotation. Does not contain extensive analysis.

- CONTRACTOR REPORT. Scientific and technical findings by NASA-sponsored contractors and grantees.
- CONFERENCE PUBLICATION. Collected papers from scientific and technical conferences, symposia, seminars, or other meetings sponsored or cosponsored by NASA.

- SPECIAL PUBLICATION. Scientific, technical, or historical information from NASA programs, projects, and missions, often concerned with subjects having substantial public interest.

- TECHNICAL TRANSLATION. Englishlanguage translations of foreign scientific and technical material pertinent to NASA's mission.

Specialized services that complement the STI Program Office's diverse offerings include creating custom thesauri, building customized databases, organizing and publishing research results ... even providing videos.

For more information about the NASA STI Program Office, see the following:

- Access the NASA STI Program Home Page at http://www.sti.nasa.gov

- E-mail your question via the Internet to help@sti.nasa.gov

- Fax your question to the NASA Access Help Desk at 301-621-0134

- Telephone the NASA Access Help Desk at 301-621-0390

- Write to:

NASA Access Help Desk

NASA Center for AeroSpace Information 7121 Standard Drive

Hanover, MD 21076 
NASA/TM-2006-214108

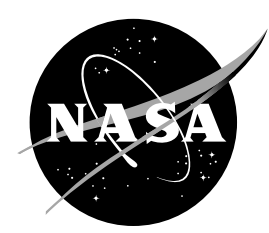

\section{Computer Aided Design of Ka-Band Waveguide Power Combining Architectures for Interplanetary Spacecraft}

Karl R. Vaden

Glenn Research Center, Cleveland, Ohio

National Aeronautics and

Space Administration

Glenn Research Center 


\section{Acknowledgments}

The author wishes to thank Rainee N. Simons, NASA Glenn Research Center, for his help and assistance towards the aforementioned work.

This report is a formal draft or working

paper, intended to solicit comments and ideas from a technical peer group.

This report contains preliminary findings, subject to revision as analysis proceeds.

Trade names or manufacturers' names are used in this report for identification only. This usage does not constitute an official endorsement, either expressed or implied, by the National Aeronautics and Space Administration.

Available from

NASA Center for Aerospace Information 7121 Standard Drive

Hanover, MD 21076
National Technical Information Service 5285 Port Royal Road Springfield, VA 22100 


\title{
Computer Aided Design of Ka-Band Waveguide Power Combining Architectures for Interplanetary Spacecraft
}

\author{
Karl R. Vaden \\ National Aeronautics and Space Administration \\ Glenn Research Center \\ Cleveland, Ohio 44135
}

\begin{abstract}
Communication systems for future NASA interplanetary spacecraft require transmitter power ranging from several hundred watts to kilowatts. Several hybrid junctions are considered as elements within a corporate combining architecture for high power Ka-band space traveling-wave tube amplifiers (TWTAs). This report presents the simulated transmission characteristics of several hybrid junctions designed for a low loss, high power waveguide based power combiner.
\end{abstract}

\section{Introduction}

Future deep space missions for NASA's "Vision for Space Exploration" demand communication systems with larger bandwidths, higher bit-rates, lower bit-error-rates, and the capability to use complex digital modulation schemes. One method to improve the current state-of-the-art is to increase the total power available in the spacecraft, thereby allowing the use of techniques typically disregarded because of high power consumption. Nuclear fission, a key component of NASA's Prometheus Program (ref. 1), can provide unprecedented power capabilities. Therefore, this paper focuses upon RF transmission systems currently capable of producing kilowatts of output power at Ka-band frequencies.

One approach to designing a kilowatt space transmitter is to combine the output of multiple power amplifiers. Power combining is a well-known technique, especially for solid-state devices. While successful for lower power levels, at Ka-band frequencies, combining state-of-the-art solid-state devices has not yielded output power above hundreds of watts. In contrast, a single space TWTA, such as the TWT developed by Boeing for a NASA GRC contract, can deliver over $180 \mathrm{~W}$ at Ka-band frequencies with a power added efficiency of 59 percent (ref. 2). Therefore, combining the power output from multiple TWTAs is a logical means to transmit kilowatts in a harsh space environment. Two methods of power combining were considered for meeting the stated goals: waveguide architectures and spatial combining architectures (ref. 3). We chose waveguide power combining architectures for their commercial availability and ease in manufacturing. In case of amplifier failure, waveguide switches can be easily included to switch in redundant amplifiers. Furthermore, because of their lower attenuation at Ka-band frequencies, waveguide structures are ideally suited for antenna beam-forming networks (ref. 4)

In this paper, we present the simulated transmission characteristics of various waveguide hybrid junctions, which are the fundamental elements of the corporate (or binary tree) power combining system being considered. Three-dimensional waveguide structures for antennas and beam forming networks have been analyzed using field theoretical techniques such as, mode matching (ref. 5) and method of moments (ref. 6). In our work, we use the commercially available CST Microwave Studio (CST of America, Inc., Wellesley, MA) (ref. 7) that uses the finite integration technique.

\section{High Power Hybrid Junctions}

A hybrid junction can be simply defined as a four port, reciprocal network with the following characteristics: power incident at one port is equally divided between two conjugate ports while delivering no power to the remaining port; power incident on two appropriate ports will form a vector sum at one port while forming a vector difference at the remaining port. Given these characteristics, as shown in figure 1, hybrid junctions are an excellent choice as the key elements for a power combiner. 


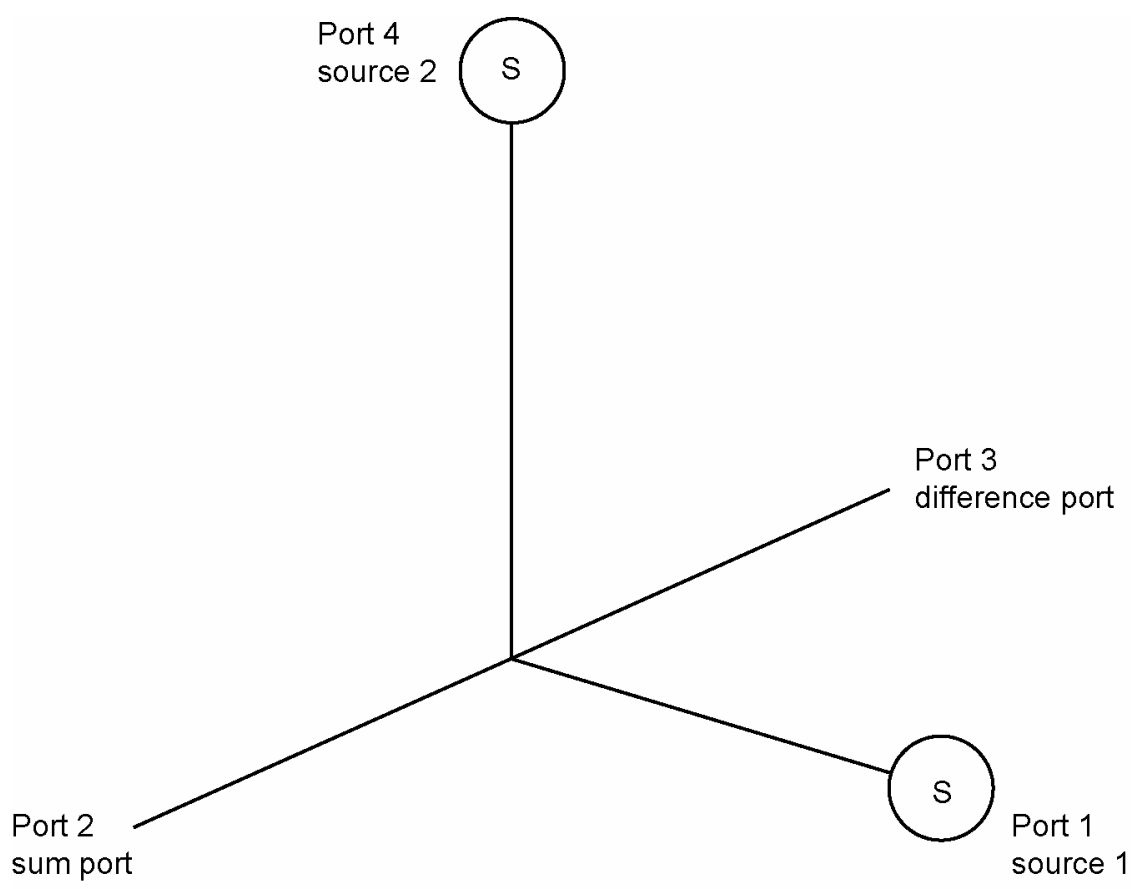

Figure 1.-Hybrid Junction as a combiner for two microwave sources with identical phase (or two phase locked microwave sources).

Waveguide hybrid junctions are commercially available; however, many vendors do not test for a power handling capability greater than a few watts, much less kilowatts (ref. 8). In addition, the tuning elements that are typically used for impedance matching (needed for maximum power transfer and power balance) are not well suited for the high powers being considered. In this power range, small structures like cones, rods and stubs can concentrate electric fields, possibly leading to RF breakdown. For these reasons, the following hybrid junctions and variants, with matching elements more suited for high powers, were chosen for analysis.

\section{Magic Tee-(Cross-Polarized Rectangular Waveguide Hybrid Junction)}

The Magic Tee, shown in figure 2, is constructed by connecting two waveguides, one as a series connection (port 4, E-arm) and one as a shunt connection (port 1, H-arm), to the center of a collinear waveguide. Power simultaneously injected into the series and shunt arms will form a vector sum at one collinear port and a vector difference and the other collinear port.

\section{Folded E-Plane Magic Tee}

The folded E-Plane Magic Tee, a variation of the Magic Tee, was developed for microwave applications where a higher power carrying capacity was required (ref. 9). This variation of the Magic Tee is created by "folding" the opposing symmetrical arms (port 2 and port 3 in figure 2) so that they are parallel to the E-arm. The heights of the "folded" arms are reduced in half. Figure 3 shows two types of folded E-Plane Magic Tees. The structure in figure 3(a) will be referred to as the "Split Collinear" Magic Tee. The structure in figure 3(b) will be referred to as the "Common Wall" Magic Tee. 

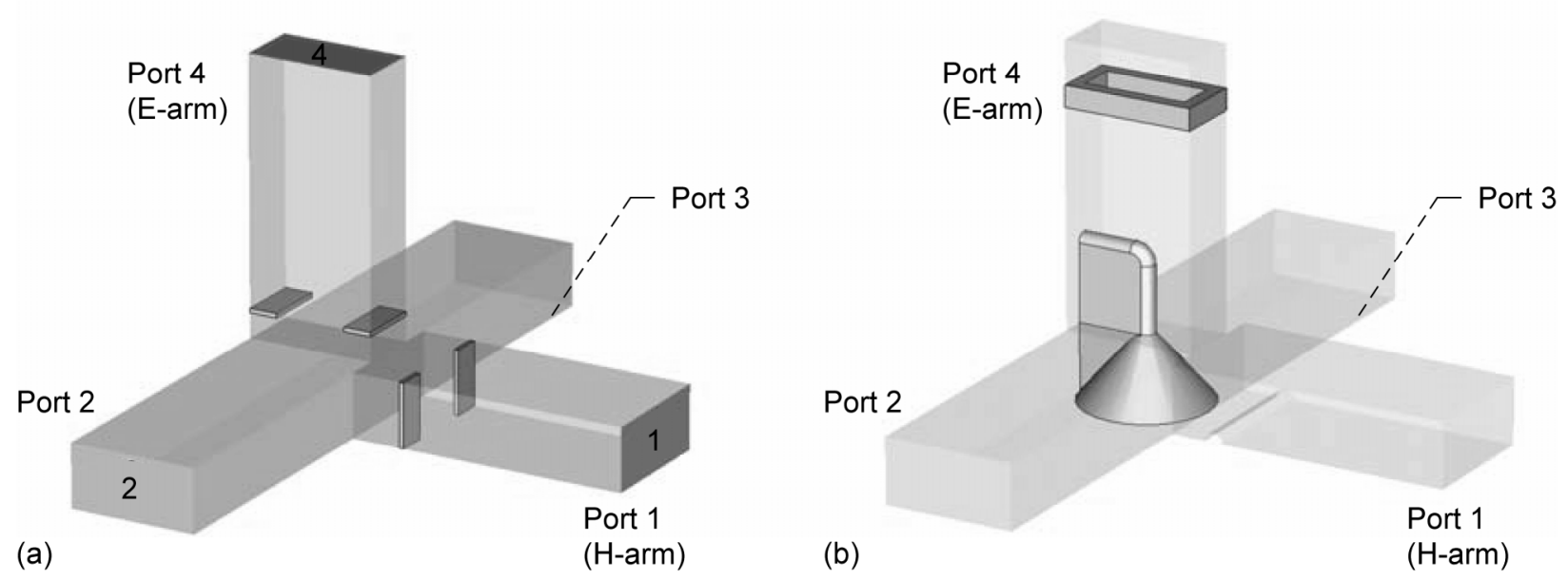

Figure 2(a).-Magic Tee matched by inductive windows. (b) Magic Tee matched by cone-fin structure.
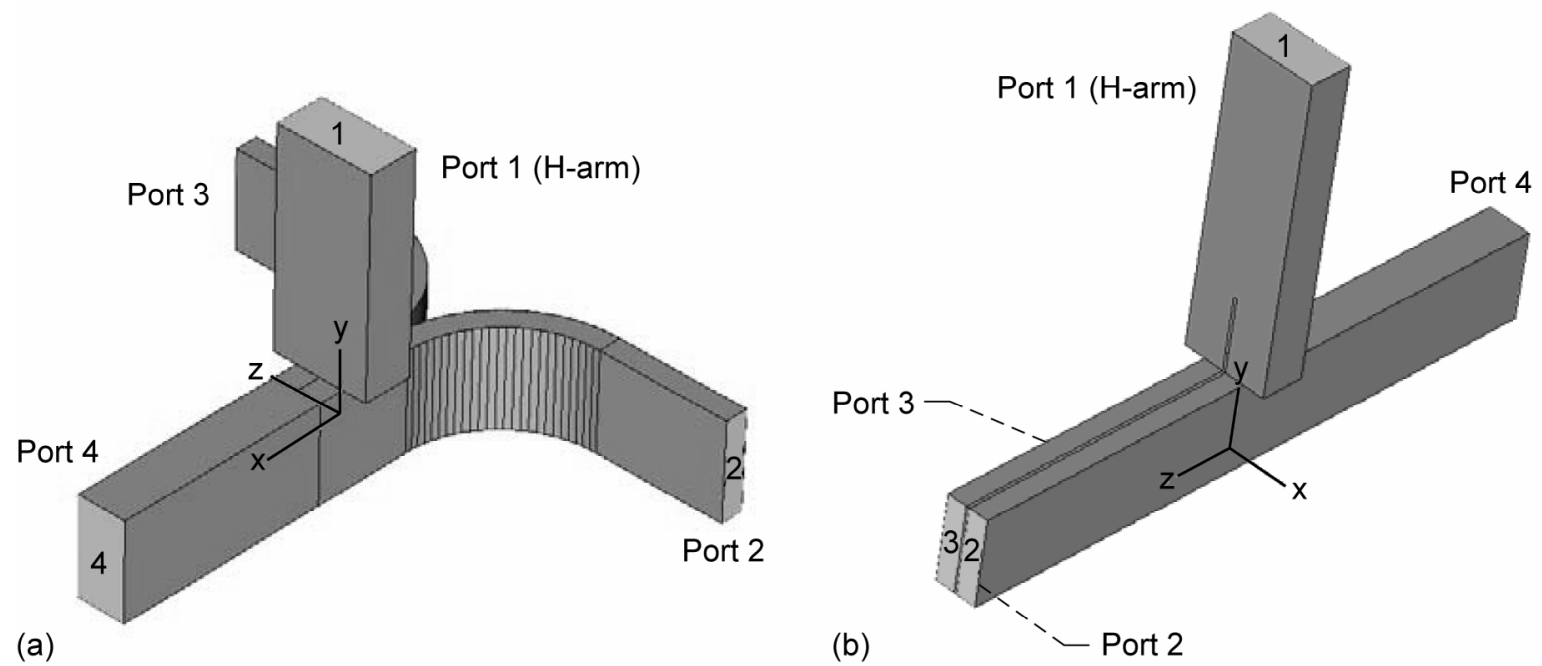

Figure 3(a)._"Split collinear arms" Folded E-Plane Tee. (b) "Common Wall" Folded E-Plane Tee.

\section{Hybrid Ring}

The Hybrid Ring is a planar hybrid junction constructed from a waveguide ring and four appropriately placed series or shunt waveguide connections. Six types of hybrid rings are shown in figure 4(a). The wellknown "Rat Race," shown in figure 4(b), is one of several hybrid rings described by Tyrrell (ref. 10).

\section{Computer Aided Design and Modeling}

There are many advanced commercial electro-magnetic simulation software packages available. Our choice of software was CST's Microwave Studio, a general-purpose electromagnetic simulator based on the Finite Integration Technique (ref. 11). This numerical technique is applicable to various electromagnetic problems, ranging from static field calculations to high frequency applications in time or frequency domain. (ref. 12) 

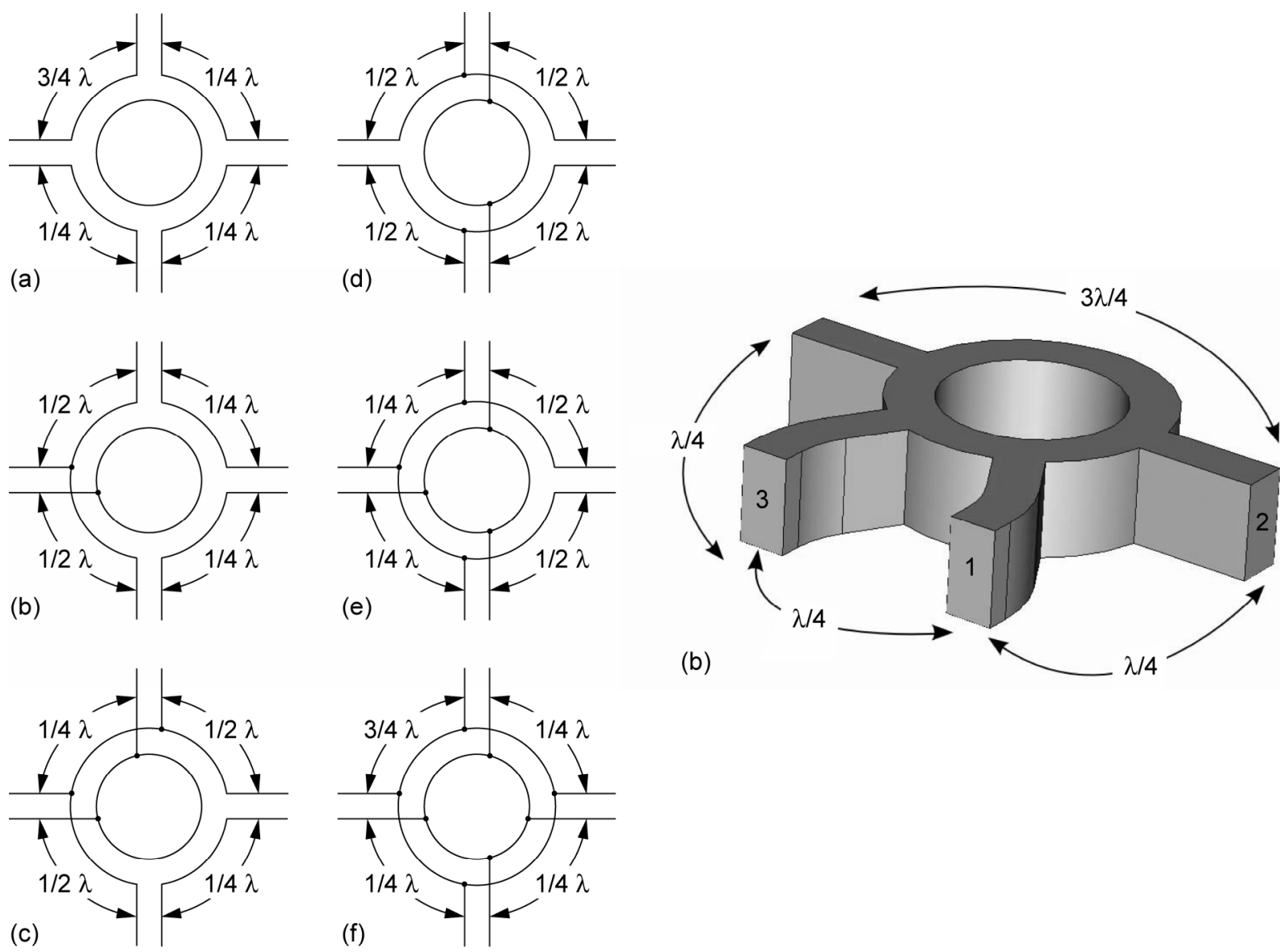

(a)

Figure 4(a).-Schematic representation of the six fundamental hybrid rings. (b) "Rat Race" Hybrid Junction.

We chose CST's Microwave Studio for several reasons including, a user-friendly interface; state-ofthe-art meshing techniques, including the ability to simulate curved surfaces within a single mesh cell; the ability to run on Windows OS (Microsoft Corporation, Redmond, Washington); the ability to use multiple CPUs; the inclusion of transient, eigenstate and frequency domain solvers; automation; optimization modules, and the ability to create one's own code with Visual Basic (Microsoft Corporation, Redmond, WA).

CST's Microwave Studio performed a time-domain analysis that included the frequency range of 31.8 to $32.3 \mathrm{GHz}$. The analyses include calculations of S-parameters, Voltage Standing Wave Ratios, and plots of the electric field intensity and power flow. The desired goals, at a center frequency of $32.05 \mathrm{GHz}$, for each device were as follows: $-3 \mathrm{~dB}$ insertion loss, a minimum of $-15 \mathrm{~dB}$ reflection loss, and a minimum of $-40 \mathrm{~dB}$ of isolation loss. All hybrid junctions were perfectly conducting, lossless circuits designed for standard WR-28 waveguides. Optimization routines refined the dimensions and locations of structures used for impedance matching.

\section{Magic Tee}

Magic Tees can be easily matched through the use of inductive or capacitive apertures (windows) at the appropriate location. For the high powers being considered, inductive irises are not the best choice for matching structures because they concentrate the electric fields thereby increasing the risk of high voltage breakdown. We have included the design of a traditional Magic Tee that is matched with inductive windows as a baseline for comparison with all the following alternative designs. For this case, shown in figure 2(a), the Magic Tee was matched with inductive irises in the $\mathrm{H}$-arm (port 1) and E-arm (port 4). 
We also modeled another design, shown in figure 2(b), where the traditional post structure was transformed into a rounded fin that extended to the back wall of the H-arm (ref. 13). A low Q inductive window in the $\mathrm{H}$-arm and a small ridge in the E-arm provided additional tuning.

\section{Folded E-Plane Magic Tee}

Khan (ref. 9) showed that the design of a well-matched Magic Tee depended solely upon maintaining symmetry while simultaneously eliminating $\mathrm{H}$-arm and $\mathrm{E}$-arm reflections. Khan also showed that due to the symmetry of the device, one can show that a thin magnetic "wall" in the symmetry plane does not affect the field incident from the H-arm, but does affect the E-arm. In the same manner, a thin electrical "wall" in the symmetry plane does not affect field incident from the E-arm but does affect the H-arm. Therefore, the cross-polarized $\mathrm{H}$-arm can be matched by extending the wall between the arms of ports 2 and 3 along the symmetry line and into the interior junction and the H-arm. Figure 5 shows the matching of the H-arm by extending the wall between the "folded" arms.

\section{Hybrid Ring}

The Rat Race (a hybrid ring with four series waveguide connections) was matched with inductive windows and small ridges located in the input and output ports. Microwave Studio ${ }^{\circledR}$ does not allow waveguide ports that are not orthogonal to the coordinate system; therefore, it was necessary to extend any ports that did not end on an orthogonal plane with E-plane bends.

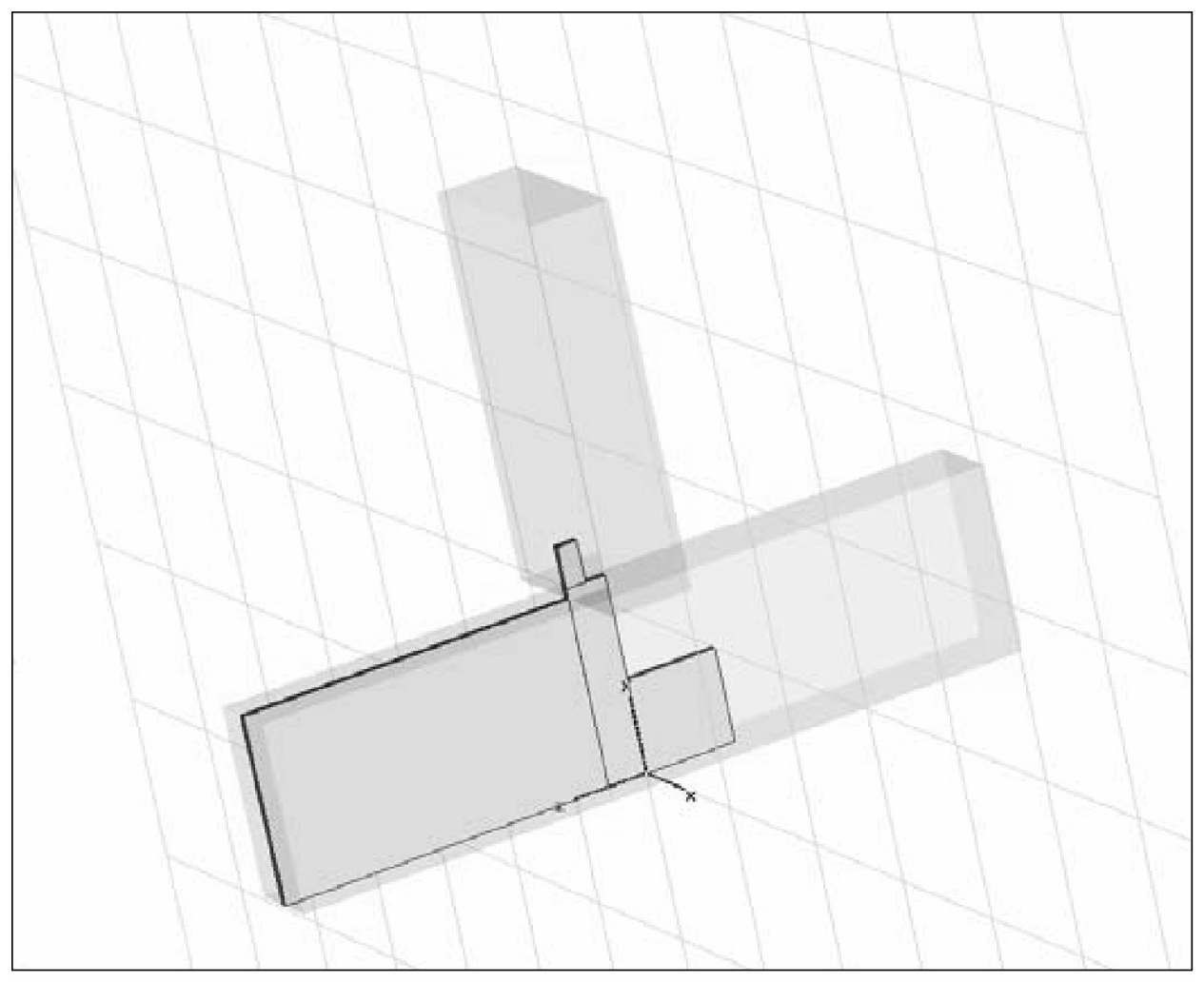

Figure 5.-Interior of Folded E-Plane Tee. 


\section{Simulated Results}

Table 1 shows a comparison of the transmission characteristics for all of the hybrid junctions that were investigated. Excluding the Magic Tee that was matched with a cone-fin structure, all discussed hybrid junctions and the structures needed for impedance matching are relatively easy to fabricate.

TABLE 1.-COMPARISON OF THE SIMULATED TRANSMISSION CHARACTERISTICS OF
THE DIFFERENT HYBRID JUNCTIONS CONSTRUCTED FROM WR-28 WAVEGUIDE
WITH A FREQUENCY RANGE FROM 31.8 TO 32.3 GHz
\begin{tabular}{|l|c|c|c|c|c|}
\hline \multicolumn{1}{|c|}{ Hybrid junction } & \multicolumn{2}{|c|}{ Insertion loss } & \multicolumn{2}{c|}{ Reflection loss } & Isolation \\
\cline { 2 - 6 } & $|\mathbf{S 2 1}| \mathbf{~ d B}$ & $|\mathbf{S 2 4}| \mathbf{~ d B}$ & $|\mathbf{S 1 1}| \mathbf{d B}$ & $|\mathbf{S 4 4}| \mathbf{~ d B}$ & $|\mathbf{S 4 1}| \mathbf{d B}$ \\
\hline $\begin{array}{l}\text { Magic Tee } \\
\text { (inductive windows) }\end{array}$ & -3.04 & -3.04 & -24.17 & -14.48 & -76.4 \\
\hline $\begin{array}{l}\text { Magic Tee } \\
\text { (cone-fin) }\end{array}$ & -3.156 & 3.426 & -15.44 & -9.823 & -136.3 \\
\hline $\begin{array}{l}\text { Folded E-Plane Tee } \\
\text { (common wall) }\end{array}$ & -3.203 & -3.124 & -13.72 & -15.9 & -151.4 \\
\hline $\begin{array}{l}\text { Folded E-Plane Tee } \\
\text { (split collinear arms) }\end{array}$ & -3.068 & -3.073 & -14.84 & -19.17 & -140.6 \\
\hline Rat Race & -3.569 & -3.467 & -10.2 & -10.42 & -27.38 \\
\hline
\end{tabular}

While the Rat Race has a narrower bandwidth than Magic Tees (ref. 10), its planar geometry allows for more convenient system architectures than cross-polarized hybrid junctions like the Magic Tee.

The Folded E-Plane Magic Tees appear to be the most promising of all devices that were investigated. The simulated characteristics of this device as a function of frequency are presented in figure 6 . These devices show the desired transmission characteristics and are easily tuned. The exceptional isolation is inherent to the cross-polarized design (ref. 10). Compared to the Common Wall Tee, the larger surface area of the Split Collinear Tee provides better heat dissipation.
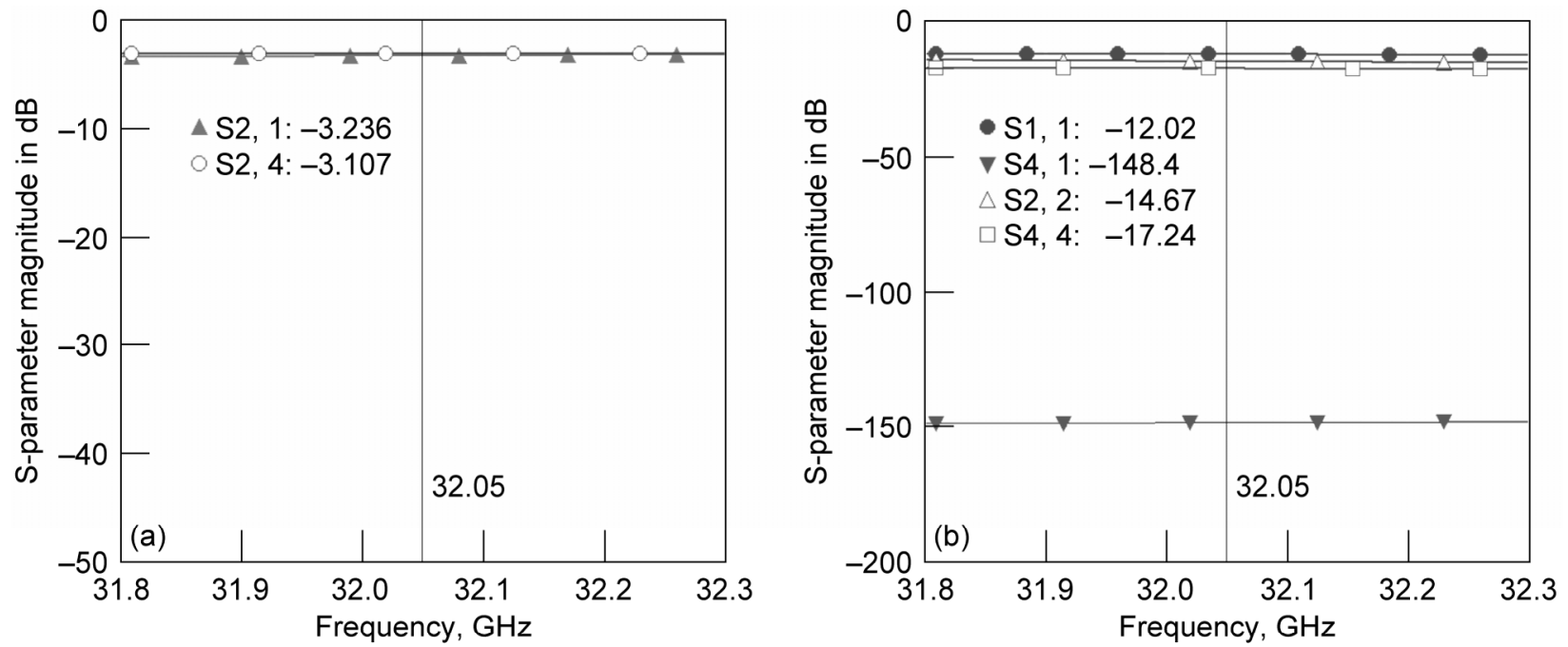

Figure 6(a).-Simulated characteristics for Folded E-Plane Tee with split collinear arms (transmission). (b) Simulated characteristics for Folded E-Plane Tee with split collinear arms (isolation and reflection). 


\section{Conclusions}

A number of Ka-band hybrid junctions have been designed using modern microwave simulation tools. Each device was matched using elements that are more appropriate for powers ranging from hundreds of watts to kilowatts. The simulations show that hybrid junctions have the desired insertion loss, good port matches with low reflection loss, and excellent isolation. Hence, the hybrid junctions can be successfully adapted for use in high power combiners for deep space communications. In addition, this preliminary study concludes that folded E-plane hybrid junctions are robust, easy fabricated and relatively inexpensive devices that are well suited for this application.

\section{References}

1. http://prometheus.jpl.nasa.gov

2. N.R. Robbins et al., "High Power, High Efficiency 32 GHz Space Traveling-wave Tube," Fifth IEEE Inter. Vacuum Electronics Conf., Monterey, CA, pp. 261-262, April 27-29, 2004.

3. K. Chang and C. Sun, "Millimeter-wave Power-Combiner Techniques," IEEE Trans. Microwave Theory Techniques, vol. 31, no. 2, pp. 91-107, February 1983.

4. R.J. Acosta et al., "Advanced Communications Technology Satellite (ACTS): Four Year System Performance,” IEEE Jour. Selected Areas in Communications, vol. 17, no. 2, pp. 193-203, February 1999.

5. F. Alessandri et al., "Computer Aided Design of Beam Forming Networks for Modern Satellite Antennas," IEEE Trans. Microwave Theory Techniques, vol. 40, no. 6, pp. 1117-1127, June 1992.

6. F. Arndt et al., "Fast CAD and Optimization of Waveguide Components and Aperture Antennas by Hybrid MM/FE/MoM/FD Methods-State-of-the-art and Recent Advances," IEEE Trans. Microwave Theory Techniques, vol. 52, no. 1, pp. 292-305, January 2004.

7. CST Microwave Studio v5.11, CST of America, Inc., Wellesley, MA.

8. Personal Communications with various microwave vendors.

9. W.K. Kahn, "E-Plane Forked Hybrid-T Junction," IRE Trans. on Microwave Theory and Techniques, vol. MTT-3, pp. 52-58, December 1955.

10. W.A. Tyrrell, "Hybrid circuits for microwaves" Proc. IRE, vol. 35, pp. 1294-1306, November, 1947.

11. T. Weiland, "A Discretization method for the Solution of Maxwell's Equations for six-component fields," Electronics and Communication, (AEÜ), vol. 31, pp. 166-120, 1977.

12. CST Microwave Studio 5 Advanced Topics Users Manual.

13. P.A. Loth, "Recent Advances in Waveguide Hybrid Junctions," IRE Trans. on Microwave Theory and Techniques, vol. 4, no. 4, pp. 268-271, Oct. 1956. 


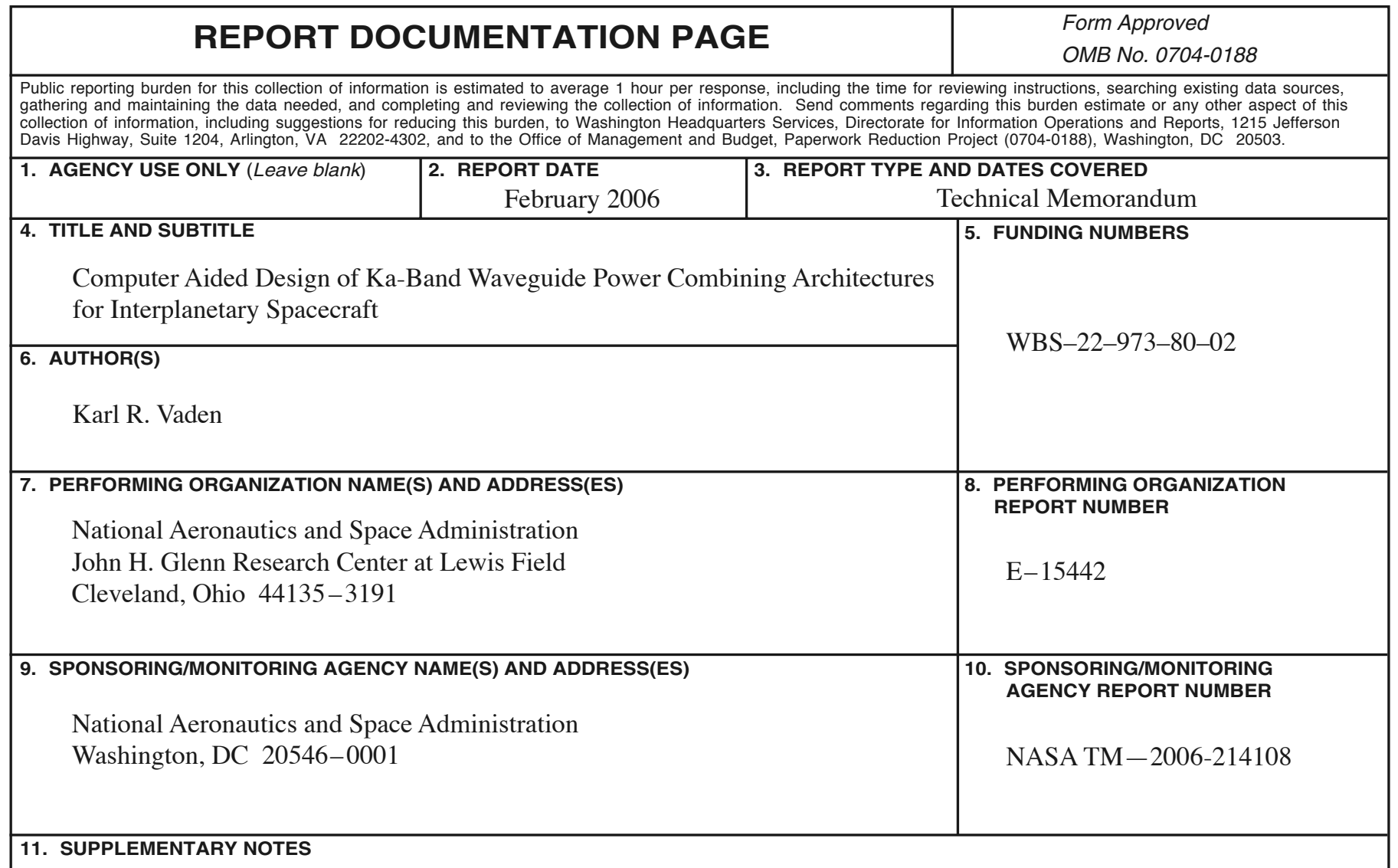

Responsible person, Karl R. Vaden, organization code RCE, 216-433-8131.

12a. DISTRIBUTION/AVAILABILITY STATEMENT
Unclassified - Unlimited
Subject Category: 32
Available electronically at http://gltrs.grc.nasa.gov
This publication is available from the NASA Center for AeroSpace Information, 301-621-0390.

\begin{tabular}{|c|c|c|c|}
\hline & \multirow{2}{*}{\begin{tabular}{|c} 
15. NUMBER OF PAGES \\
13 \\
\end{tabular}} \\
\hline \multicolumn{3}{|c|}{ Power combinino. Numerical simulations. Waveouide hybrid iunctions } & \\
\hline $\begin{array}{l}\text { 17. SECURITY CLASSIFICATION } \\
\text { OF REPORT }\end{array}$ & $\begin{array}{l}\text { 18. SECURITY CLASSIFICATION } \\
\text { OF THIS PAGE }\end{array}$ & $\begin{array}{l}\text { 19. SECURITY CLASSIFICATION } \\
\text { OF ABSTRACT }\end{array}$ & 20. LIMITATION OF ABSTRACT \\
\hline Unclassified & Unclassified & Unclassified & \\
\hline
\end{tabular}



